small increase of probable error, say 40 per cent., appearing when the dispersion is divided by three.

In the early-type stars the diffuseness of the available lines in the spectrum increases the probable error very rapidly, and Mr. Plaskett is convinced that physical causes in the star's atmosphere are contributory to this increase.

For solar-type stars it would appear that the average probable error of a good three-prism determination need not exceed $\pm 0.5 \mathrm{~km}$. per sec., while with one prism $\pm 0.70 \mathrm{~km}$. might be expected in good work. If stars of an earlier-type spectrum are dealt with, \pm 2 to $\pm 11 \mathrm{~km}$. per sec. is a moderate estimate of the probable error. Finally, Mr. Plaskett suggests that with solar stars the greater part of the error accrues from instrumental causes, the errors of measurement only accounting for about onethird or less.

The Photographic Magnitudes of Stars.-In Circular No. 160 of the Harvard College Observatory Prof. E. C. Pickering discusses the progress made, to July, in the establishment of a method for determining photographic magnitudes and of a scale for recording them.

Three methods have been found to give satisfactory results. The first depends upon the law that stars of the same spectral class have the same colour and has been tested with concordant results; the following values are interesting as giving the constants necessary to reduce photometric to photographic magnitudes according to spectral class :-

$$
\begin{array}{cccccc}
\mathrm{B} & \mathrm{A} & \mathrm{F} & \mathrm{G} & \mathrm{K} & \mathrm{M} \\
-0.3 \mathrm{I} & \mathrm{O} 0 \mathrm{O} & +0.32 & +0.7 \mathrm{I} & +\mathrm{I} \cdot \mathrm{I} 7 & +\mathrm{I} \cdot 68
\end{array}
$$

Thus if the visual magnitude of a star is 5.00 and the spectrum is of type $B$, the photographic magnitude is 4.69 , but if the spectrum is of the $G$ type the photographic magnitude is $5.7 x$.

The second method, in which a standard "polar sequence" of stars is photographed on the same plate and under similar conditions as the stars to be measured, has been already described in these columns, but it is interesting to note that the work has been extended to stars so faint as the twentieth magnitude, and it is hoped, ere long, to publish definitive magnitudes for a great number of stars in both hemispheres. About II, measures of 200 photographs have already been made; for stars fainter than magnitude 14, for which long exposures are necessary, it has been found that this method is not so suitable. For such stars it has been found that the third method, in which a small circular prism of very small angle is attached to the centre of the objective, is better; the small prism diverts a known proportion of the light from each image into a secondary image, and so provides a ratio scale. Prof. Pickering discusses the difficulties presented by the problem, and states that although the results already attained are very hopeful, much remains yet to be done.

The same problem is also attacked by Herr E. Hertzsprung in No. $445^{2}$ of the Astronomische Nachrichten, who proposes a tried method in which the density of a direct image is compared with an image, on the same plate, produced when a grating is placed before the objective.

Proper Motion of the Star B.D. $+33^{\circ}$ 99.-Whilst making observations of the minor planet 19 10 $\mathrm{KU}, \mathrm{Dr}$. Abetti was led to suspect that one of his comparison stars, B.D. $+33^{\circ} 99$ (AG. Lei. 226), has a large proper motion. Subsequent investigation and calculations show that this proper motion amounts to $-0.027 \pm 0.004 \mathrm{~s}$. and $-0.34 \pm$ $0.00^{\prime \prime}$. The magnitude of this star is 8.5 (Astronomische Nachrichten, No. 4453).

\section{THE NEW METEOROLOGICAL OFFICE.}

$\mathrm{O}$ Thursday, December I, a large party assembled at the new Meteorological Office at the corner of Exhibition Road and Imperial Institute Road on the invitation of the Meteorolngical Committee.

The committee was originally appointed by H.M. Treasury in 1905 to control the administration of the Parliamentary grant for meteorology. Its inexpressive title gives little indication of its responsibility to the NO. 2 I 45 , VOL. 85$]$ country and, indirectly, to the world at large. It consists of the director of the office, Dr. W. N. Shaw, who is ex officio chairman; the hydrographer of the Navy, RearAdmiral H. E. Purey Cust; Mr. G. L. Barstow, of the Treasury; Captain J. M. Harvey, of the Board of Trade; Mr. T. H. Middleton, of the Board of Agriculture and Fisheries; with Sir G. H. Darwin, F.R.S., and Prof. Arthur Schuster, F.R.S., the nominees of the Royal Society.

The work of the office goes back, in continuity, to the original establishment of a Meteorological Department of the Board of Trade for the joint service of the Navy and the mercantile marine under the superintendence of Admiral FitzRoy, the naval officer who, as captain of the Beagle, had carried Charles Darwin round the world. The motive power for the establishment of a special department for meteorology came from a maritime conference held in Brussels in 1853 , in which Lieut. Maury, of the United States Navy, a well-known geographer and meteorologist, took a leading part. The primary object of the office was the collection and discussion on an organised plan of meteorological observations made at sea; but when Leverrier began collecting daily observations by telegraph in France, FitzRoy associated himself with the idea, and in 1860 he introduced a system of weather telegraphy with storm warnings and forecasts which in $186 \mathrm{I}$ were published in the newspapers.

This line of action evoked a great deal of criticism on the part of scientific authorities, and it is doubtful whether meteorology, at that time a bashful débutante among the sciences, has ever been forgiven for so shocking a faux pas. It is true that the system of warnings was continued after FitzRoy's death at the instance of the Board of Trade, influenced by several memorials to Parliament, and that in 1879 , after the issue of forecasts had been dutifully suppressed for twelve years, in a report of the council then in control of the office, appointed by the Royal Society and made up of the great names of Henry J. S. Smith, Warren De la Rue, Frederic J. O. Evans, Francis Galton, George Gabriel Stokes, and Richard Strachey, the following paragraph appears:- "For several years forecasts not intended for publication had been daily prepared in the office, and the experience thus gained by the staff has emboldened the council to announce their readiness to commence in April, 1879, the issue to the public of forecasts for the different parts of the United Kingdom," and that the issue has been continued ever since; but the natural hesitation which men of science feel about publishing their conclusions before they have had an opportunity of verifying them has always overshadowed that side of the office work. To that circumstance, combined with the frigidity with which the young science has been treated by her elder sisters, it is probably due that, while prolonged effort has been devoted to the preparation of forecasts twice, or even three times a day, for a whole generation, and while the rule that no forecast shall be formulated without first setting out the data and the grounds for the inference has been rigorously enforced, yet the issue of the forecasts has been left practically to the newspapers. It seems otherwise inexplicable that no general system of distribution of forecasts by telegraph should have been adopted in this country.

FitzRoy died in 1865, and the office became the subject of inquiry by a Government committee, with the result that in 1867 the control of the Parliamentary grant was handed over to a committee of the Royal Society, with Sir E. Sabine, the president of the Royal Society, as chairman. At the same time provision was made for marine meteorology and weather telegraphy to be associated with the work of fully equipped meteorological observatories of the first order, six of which were forthwith established, namely, Falmouth, Stonyhurst, Aberdeen, Glasgow, Armagh, and Valencia, in addition to Kew, which had become the central observatory of the system.

Continuity between FitzRoy's department and the Meteorological Office was maintained by the transfer of all the duties of the department and a number of members of the staff to the new committee. Mr. T. H. Babington, however, who took over the management of the department on FitzRoy's death, was not transferred; Mr. R. H. Scott was appointed director of the new establishment with 
Captain H. Toynbee as marine superintendent. The office occupied the quarters at $\mathrm{I}$ and 2 Parliament Street, belonging to the Board of 'Trade, which accommodated FitzRoy's department; but to its chagrin it was dispossessed in r869, and the ejected committee hired accommodation for itself in the form of a residential flat over a shop at i16 Victoria Street.

In 1875 another Government committee of inquiry was constituted, with the result that in 1877 the direction of the office became vested in a council appointed by the Royal Society. This constitution lasted until 1905, when, as the result of a third committee of inquiry, the present system was adopted, under which the office is managed by a director with an advisory committee appointed by the Treasury. Throughout the period of the council the office occupied the premises at in 6 Victoria Street, which during its tenure was renumbered 63 .

It cannot be said that the council regarded the suite of offices which they occupied as ideal accommodation for the Office; but it was generally hampered for want of funds, and, as a matter of practical politics, the idea of new accommodation may be attributed to Sir H. Maxwell's committee of 1903, which pronounced the accommodation at Victoria Street to be unsuitable. The advantage of housing the office under the same roof as a post office had long been recognised, and the wish of the Post Office to have a permanent structure at South Kensington on land which formed part of the estate of the Commission for the Exhibition of $185 \mathrm{I}$ led, at the suggestion of a member of the Meteorological Committee, to an arrangement by the Treasury for the committee to rent from H.M. Office of Works more spacious accommodation than they had at Victoria Street at practically the same rent. The arrangement was concluded in May, 1907, and the transfer of the work to the new premises was completed on November 15 , 1910. The party on December I was intended to give those interested in the work of the office an opportunity of seeing the new premises newly equipped.

This long introduction is necessary, because the office has now fifty-six years of history behind it, passed in a habitation chosen with a view to the collection and discussion of observations from sea and land. During that time it has been responsible for supplying meteorological instruments to the Navy, the mercantile marine, its own stations, and recently to colonial Governments, and it has become the controlling centre of more than 500 stations of various kinds in these islands and in various colonies, while it has instruments on more than 200 ships afloat, and is in direct communication with nearly all liners crossing the Atlantic. It has made a vast collection of observations from ships in the form of log books which fill 500 feet of shèlving. It deals with about 50,000 telegrams a year in its telegraphic branch. The independent existence of the British Rainfall Organisation, founded as a private enterprise by Mr. G. J. Symons, a member of FitzRoy's staff, exonerates it from dealing fully with the statistics of rainfall, but for more than forty years it has aided the meteorological societies of London and Edinburgh in the collection of climatological data for the British Isles, and has gradually become itself a centre for the compilation of returns from volunteer observers all over the country and from some of the colonies. To this collection is added the published meteorological data of all the countries of the world, forming a library almost unique of its kind. It has issued publications to the number of about 250 volumes, which, being in the form of Bluebooks or of unwieldy atlases or charts, are little read. So far as the general public is concerned, it appeals to them only through the forecasts which the newspapers are kind enough to issue for it, through the storm signals which are occasionally visible on the coasts, and through certain fishery barometers supplied to coast stations, which are, however, mostly marked with the initials B.T., because the official in charge was unwilling to recognise as de jure the disscciation de facto of the office from the Board of Trade.

Until quite recently, partly on account of the apathetic attitude of the universities, partly because meteorology deals with British units and other sciences use metric units, the education of the people in the new science had not ever been begun. The meteorology of Daniell and
Herschel had been, in fact, allowed to fall out of the educational curriculum, and its place was taken by sciences with which the teachers were themselves acquainted.

In moving their homc from Victoria Street to South Kensington the Meteorological Committee has set itself to change all this. They have sought to secure, with what success the public may now judge, space in which their collection of books and records can be reasonably well housed, and which at the same time affords an opportunity to display, for the information of the public, a series of exhibits which show what the work of the Meteorological Office has been in the last fifty years, what its work is now, how it does it, and what its purpose is in doing it. Those who have visited the office will agree that the idea of combining a library with a museum has elicited very generous sympathy from the Office of Works, and that the architect of the new building, Sir H. Tanner, has dealt with the problem, which is not without difficulty, in a manner for which admiration is not too strong a term to use. The space is perhaps a little over full, as the library has even now to accommodate part of the working staff of the office in addition to its other requirements; but when it is remembered that rent is still a consideration to be reckoned with by the committee, there is, after all, little to complain of.

The office premises are mainly on the first and second floors of the new building at the corner of Exhibition Road and Imperial Institute Road. These two floors provide, besides the library and its ante-room, a room for the director and rooms for the four superintendents and for the director's secretary, a large room for the clerical staff and another for the forecast staff, three rooms for the marine staff, and two for the instruments staff. To judge by external appearances, the whole building might be regarded as a post office, but it is not so. The ground fioor and the greater part of the basement is assigned to the post office, but in the basement the Meteorological Office has space which it is hoped may provide for a printing office as well as a workshop. A small physical laboratory is provided on the third floor, the remainder of ' which is temporarily occupied by the staff of the Science Museum. Access is given thereby to a large flat roof, which provides invaluable opportunity for the exposure of instruments for the purposes of trial and investigation.

The manner in which the committee have utilised the space at their disposal and have kept in view the educational purposes which have been indicated will be evident from the list of exhibits prepared for the party on December $\mathbf{r}$.

In a case outside the doorway is exhibited the most recent information about the current weather, based on the telegrams received. In the outer lobby, opposite the door of the post office, is a case containing a barograph, the recording apparatus of a Callendar thermograph, and of a Dines pressure-tube anemograph, exhibiting the continuous record of pressure, temperature, and wind velocity. On the walls of the inner lobby and the staircase leading to the first floor are a series of frames showing the course af the seasons in the British Isles as determined by the weekly averages since 1878 . The relation thereto of the weekly values of the current season for four divisions of the country is shown upon transparent paper, which covers the diagrams of average variation. These diagrams lead up to one which shows how the meteorological elements at the several stations in the same district may vary under similar types of weather. Four frames show the monthly meteorological charts of the Atlantic and Indian Oceans, and further on is a diagram showing the variation of temperature in the upper air on various occasions in 1908 up to 15 miles or more, in juxtaposition with a series of photographs of clouds presented to the office by $\mathrm{Dr}$. W. J. S. Lockyer.

The catalogue of exhibits makes reference to a series of three cases on the first-floor hall intended to illustrate the work of the office under FitzRoy at the Board of Trade, under Sabine and Scott, of the Meteorological Committee of the Royal Society, and under the Meteorological Council, with Smith and Strachey, successively, as chairman, but for reasons not given in the programme the cases are not yet there; some of the exhibits are to be found compressed into a single case in the upper corridor. 
The hall accommodates, however, a radiation recorder by Callendar and a hyetograph or rain recorder of Negretti and Zambra's most recent pattern.

From the hall we pass to an ante-room provided with a counter for the supply of information of various kinds, and leading to the library and museum on the one side and to the headquarters of the clerical and inquiry staff on the other. This room, with the library and the staircase, are finished throughout with ornamental woodwork in Austrian oak. Round the ante-room are glass cases for the display of barograms from ships and land stations, anemograms and other records of importance to aeronauts, and also cases devoted for the present to diagrams prepared in the office to show results deduced from data for the whole globe or for British observatories or stations, including the relationships of meteorology and agriculture. A diagram, newly prepared, showing the distribution of rainfall throughout the day for the several months of the year at Kew and Valencia, is specially noticeable. In the same room is the Kelvin harmonic analyser constructed for the council to be used for the analysis of barograms and thermograms. A relief map of the British Isles on the scale of one-millionth, intended for the central space, being unfinished, was represented by a cast of the English section.

On either side of the entrance to the libraty and museum are square kiosks for envelopes, the faces of which are framed in glass and used for displaying the weekly sets of records from observatories, the records of sunshine at ninety-two stations for a single day of last summer, and the winter sunshine records of 1909-10 in London, Cambridge, and Eastbourne. Within the library, in four cases, are displayed a series of exhibits in connection with marine meteorology, the daily service of forecasts and stormwarnings, climatological statistics, and the investigation of the upper air. Another and larger case is devoted to the observatories at Kew and Eskdalemuir. Four small cases show a new method of representing data for the whole world on what is called a developable globe. The current daily weather charts of all countries and the latest climatological reports from the British Dominions are collected together in special cabinets. Two glass cases face one as one enters the museum : one contains specimens of the normal instruments adopted by the office, the other such examples as the office possesses of the corresponding instruments of other countries.

The library is divided into six compartments by bookcases extending from the side walls. In four of the compartments the books of published data are grouped according to countries, the remainder being occupied by periodicals, text-books, \&c. The recesses of three of the bays are used by the working staff of the statistical and library division of the office; two are furnished with tables for students, and on the book-cabinets near by the latest additions to the library are displayed. A few educational exhibits, lantern-slides, photographs, \&c., including some valuable stereophotographs of clouds from a long base, by Mr. J. Tennant, were set on Thursday on one of the tables.

The library is not large enough to contain all the books and documents belonging to the office. Accordingly, the manuscript records of observations at stations of various kinds find a place in the room of the superintendent of statistics. The original working charts of the Daily Weather Service are housed with the files of daily synchronous charts of all kinds in the forecast room, a spacious room on the second floor in direct connection by means of pneumatic tube with the instrument room of the post office. The series of meteorological logs from ships, now exceeding 13,000 in number, is housed in the working rooms of the marine staff; the books of data extracted from them are in the marine superintendent's room or in the passage near by. The stock of instruments is housed in the rooms of the instruments staff, while separate store rooms are set apart for publications and for observatory records. These latter are already too numerous for the accommodation provided. The bound volumes of anemograms are therefore stored on shelves elsewhere, and for the time being the sunshine cards are in the basement, where it is proposed to construct with them a $\mathrm{I} 3$-inch wall 50 feet in length and ro feet high.

One of the main difficulties connected with the removal has been the housing of the enormous collection of records and documents, the accumulation of upwards of fifty-six years. The problem of the ultimate fate of these accumulations is one which has now to be faced.

The new arrangement of the office, which is open to the public, has chiefly in view the educational advantages which a library and museum can afford; but it has another object. One often hears a distinction drawn between routine and research, sometimes to the disparagement of the work of an office. Routine work in meteorology is really and truly cooperative research; if not it ought to be discontinued, for it has ceased to have any object. Research in the more restricted sense means personal research upon a subject selected by the individual taste. In cooperative research one cannot choose one's subject; it has been chosen for us by international agreement, by conferences and congresses, by committees perhaps, or by other circumstances over which we have no immediate control. What is still left to our free choice is whether the cooperative research shall be manifestly our research or other people's research. Routine becomes sterile when it is a listless contribution to other people's research. To keep cooperative research alive we need to keep verv close up to the working face of the bore into the unknown. It may take a generation or more to carry the whole work through, and premature publication may be worse than routine. To put the record of our progress in a shape in which it can be seen by those who appreciate it, as well as those who do not, gives us a place in the ranks of conscious workers for a definite, even if a distant, object.

W. N. SHaw.

\section{THE CLAIMS OF SCIENTIFIC RESEARCH.}

THE anniversary dinner of the Royal Society was held as we went to press last week. Lord Robson proposed the toast of "The Royal Society," and it was replied to by Sir Archibald Geikie, K.C.B., president of the society In the course of his remarks, Lord Robson pointed out that in nearly every direction the labour and research of science, however remote they may sometimes seem from the affairs of the workshop or the office, are opening up new and almost illimitable sources of wealth and new avenues of profitable employment. It is the man of science who is to decide the fate of the tropics; not the soldier, or the statesman with his programmes and perorations, but the quiet entomologist. $\mathrm{He}$ is the man of science who of all others strikes popular imagination the least, and gets less of popular prestige; but he has begun a fascinating campaign for the sanitary conquest of those enormous tracts of the earth, and before long he will have added their intensely fertile soil, almost as a free gift, to the productive resources of the human race. The report in the Times states that Lord Robson continued as follows :"Not long ago it was my duty to consider legislation in reference to the most complicated problems of overcrowding in cities. That is essentially a problem for statesmen, but not for statesmen alone. Perhaps the most hopeful attack on overcrowding is being unconsciously made by those men of science who have lately done so much to improve the transmission of electric power. They are on the way to make it possible and profitable for factories to establish themselves away from cities and coalpits, and yet have the exact amount of power they want each day for their machinery sent down to them every morning by wire at a trivial cost. Some day manufacturers will begin to go back to the land, and we shall regard engine-building or soap-boiling as rural occupations. We look to you, the men of science, and almost to you alone, to ensure, not only that our centres of population shall not be congested, but also that our cities, now smokeladen and devitalised, shall not be polluted. I have spoken of a sanitary conquest of the tropics. Give us also a sanitary conquest of the air of England. What a programme of social reform the Royal Society has got! Yet I have not heard that you are making any claims on the Development Fund. In all seriousness and earnestness, I contend that you ought to be the most favoured, as you would certainly be the most meritorious, of all claimants on that reservoir of national generosity. The various sections and interests who are on the way to absorb it all

No. 2 I 45 , VOL. 85$]$ 